\title{
Poly(ethylene terephthalate) surface modification by deep UV (172 $\mathrm{nm})$ irradiation
}

\author{
Zhengmao Zhu', Michael J. Kelley ${ }^{\mathrm{a}, \mathrm{b}, *}$ \\ ${ }^{\mathrm{a}}$ Department of Applied Science, College of William and Mary, Applied Research Centre, 12050 Jefferson Avenue, \\ Suite 601, Newport News, VA 23606, USA \\ ${ }^{\mathrm{b}}$ Free Electron Laser Department, Jefferson Lab, 12000 Jefferson Avenue, Newport News, VA 23606, USA
}

Received in revised form 27 February 2004; accepted 11 May 2004

Available online 19 June 2004

\begin{abstract}
The prospects of obtaining desired surface-mediated characteristics while retaining bulk-mediated physical properties and avoiding potential environmental issues with wet chemical technology lends considerable appeal to photochemical approaches. We investigated the response of poly(ethylene terephthalate) to $172 \mathrm{~nm}$ UV from a xenon excimer lamp in the absence of oxygen, using XPS, ToF/SIMS, and AFM. The main effects are increasing loss of a $\mathrm{C}=\mathrm{O}$ moiety and carboxylic acid production without effect on topography upto a total fluence of $16 \mathrm{~J} / \mathrm{cm}^{2}$. Above this level no further change in surface chemistry was evident, but surfaces became rougher, suggesting the onset of etching.
\end{abstract}

(C) 2004 Elsevier B.V. All rights reserved.

PACS: 81.65.Ya; 82.50.-m; 82.35.+t

Keywords: Surface modification; Surface characterization; Excimer lamp; Polymer photochemistry

\section{Introduction}

Improved value in use of major commercial polymers will come chiefly from enhanced surface or interface properties: adhesion, increased (or decreased) permeability, antisoil, and antimicrobial functionality. Poly(ethylene terephthalate) (PET) is an especially attractive target because of its wide use in textiles and packaging, though all applications

\footnotetext{
* Corresponding author. Present address: Department of Applied Science, College of William and Mary, Applied Research Center, 12050 Jefferson Avenue, Suite 601, Newport News, VA 23606, USA. Tel.: +1-757-269-5736; fax: +1-757-269-5755

E-mail address: mkelley@jlab.org (M.J. Kelley).
}

are highly cost sensitive so that wet chemical (fiber finishes) or extrusion coatings (films) dominate. An alternative, potentially attractive approach would take advantage of the ability of UV light to drive radical processes to transform surface chemistry.

There are few reported studies of the effect of deep $(<250 \mathrm{~nm}) \mathrm{UV}$ on PET. No effect was found by XPS for excimer laser irradiation in air at $248 \mathrm{~nm}$ of biaxially oriented film at $12 \mathrm{~mJ} / \mathrm{cm}^{2}$ (below the ablation threshold) [1]. For $193 \mathrm{~nm}$ irradiation in nitrogen, a loss of oxygen-containing species is evident by XPS even at $10 \mathrm{~mJ} / \mathrm{cm}^{2}$ [2]. C-O was affected more than $\mathrm{C}=\mathrm{O}$. Even though the fluence in both excimer laser studies was below the ablation threshold, thermal effects were not absent, since the polymer 
was amorphized in both cases. Irradiation with $185 \mathrm{~nm}$ $\mathrm{Hg}$ vapor light in vacuum led to reduced surface oxygen as seen by XPS, but increased uptake of derivatizing reagents for carboxyl functionality [3]. In contrast, repeating the experiment with a filter that excluded $185 \mathrm{~nm}$ emission and passed only the $254 \mathrm{~nm}$ component resulted in little or no effect [3], consistent with the $248 \mathrm{~nm}$ observations. Irradiation in nitrogen at $222 \mathrm{~nm}(\mathrm{KrCl}$ excimer lamp) resulted in a modest increase in surface oxygen species as seen by XPS, but only after $500 \mathrm{~J} / \mathrm{cm}^{2}$ [4]. At this fluence level, the question of a possible role for residual oxygen in the treatment cell atmosphere is hard to avoid.

Nonetheless, the effect of UV wavelength at these low fluences suggests that interesting (and perhaps useful) photochemistry may be taking place. Advances in UV sources, surface characterization and computational modeling motivate us to revisit the investigation of the effect of deep UV radiation on PET.

\section{Experimental}

\subsection{Excimer laser exposures}

It seemed appropriate to connect the present work with the previous studies by carrying out a few excimer laser exposures. The PET used was $12 \mu \mathrm{m}$ thick commercial production Mylar ${ }^{\circledR}$ LB 48 film (Dupont). We used a Lambda LPX 325i having either an $\operatorname{ArF}(193 \mathrm{~nm})$ or $\operatorname{KrF}(248 \mathrm{~nm})$ fill, with the beam spread by a cylindrical lens to obtain the desired fluence as a single shot. About $1 \mathrm{~cm}$-wide strips of the film were rinsed with HPLC grade isopropanol and end-mounted in $35 \mathrm{~mm}$ slide holders. The irradiations were accomplished in a homemade chamber continuously swept by boil-off from liquid nitrogen.

\subsection{Excimer lamp exposures}

The rest of the UV-irradiations were accomplished with a dielectric barrier discharge (DBD) excimer lamp of our own construction; a detailed review of such lamps may be found in [5]. The annular configuration consists of an inner quartz tube to carry cooling water, an annular space for the active gas, and a
$43 \mathrm{~mm}$ diameter outer Suprasil ${ }^{\circledR}$ quartz tube, $50 \mathrm{~cm}$ in length. The lamp was operated at atmospheric pressure filled with undiluted xenon gas (Spectra Gas Laser Grade) to produce $172 \mathrm{~nm}$ UV. The lamp is enclosed within a coaxial polycarbonate cylinder, sealed at the ends and continuously swept by boiloff from liquid nitrogen. The material to be treated was attached to the inner surface of the enclosure, providing a constant distance to the lamp of about $7 \mathrm{~cm}$. The irradiance at the sample position was measured with an International Light Model 1400A photometer with a SED-185 detector head. The spectral energy distribution of the lamp and the detector response curve do not overlap perfectly, necessitating a correction factor of 2 to the meter reading to obtain the UV dose. Average irradiance received at sample position is about $50 \mathrm{~mW} / \mathrm{cm}^{2}$. Multiple samples were acquired at UV dose levels of $4,8,16$, and $32 \mathrm{~J} / \mathrm{cm}^{2}$. In each case, a piece of polyethylene (PE) film was treated along with the PET. If subsequent XPS showed other than trace oxygen pick-up by the PE, the run was discarded.

\subsection{Surface analysis}

Samples for surface analysis were rinsed with isopropanol (Fisher, HPLC grade) and then deionized water (>18 M $\Omega$ ) prior to introduction, with the exception of one set of samples exposed to $32 \mathrm{~J} / \mathrm{cm}^{2}$. XPS analysis of the $172 \mathrm{~nm}$ treated material was carried out with a Specs "PHOIBOS" system, using a Mg anode $(1253.6 \mathrm{eV})$ operated at $15 \mathrm{kV}$ and $200 \mathrm{~W}$. To better reveal the surface functional group population, a complete set of samples was derivatized with silver trifluoroacetate [3] by overnight $(18 \mathrm{~h})$ exposure to a $10^{-2} \mathrm{M}$ solution of $\mathrm{AgOCOCF}_{3}$ in acetone and then washed repeatedly with acetone. XPS of the laserirradiated materials employed a VG ESCALab, also with a $\mathrm{Mg}$ anode.

Time of flight secondary ion mass spectrometry (ToF/SIMS) provides a more sensitive surface analysis [6] and is especially effective for polymers [7]. We used a PHI "TRIFT II CE" instrument to raster a $200 \mu \mathrm{m} \times 200 \mu \mathrm{m}$ surface area with $15 \mathrm{keV}$ gallium ion beam at $600 \mathrm{pA}$ current with extraction voltage set at $7200 \mathrm{~V}$. Data acquisition time was set for $5 \mathrm{~min}$ and sample surface received an ion dose of $2.4 \mathrm{E}+11 \mathrm{ion} /$ $\mathrm{cm}^{2}$. Surface topography was characterized by atomic 


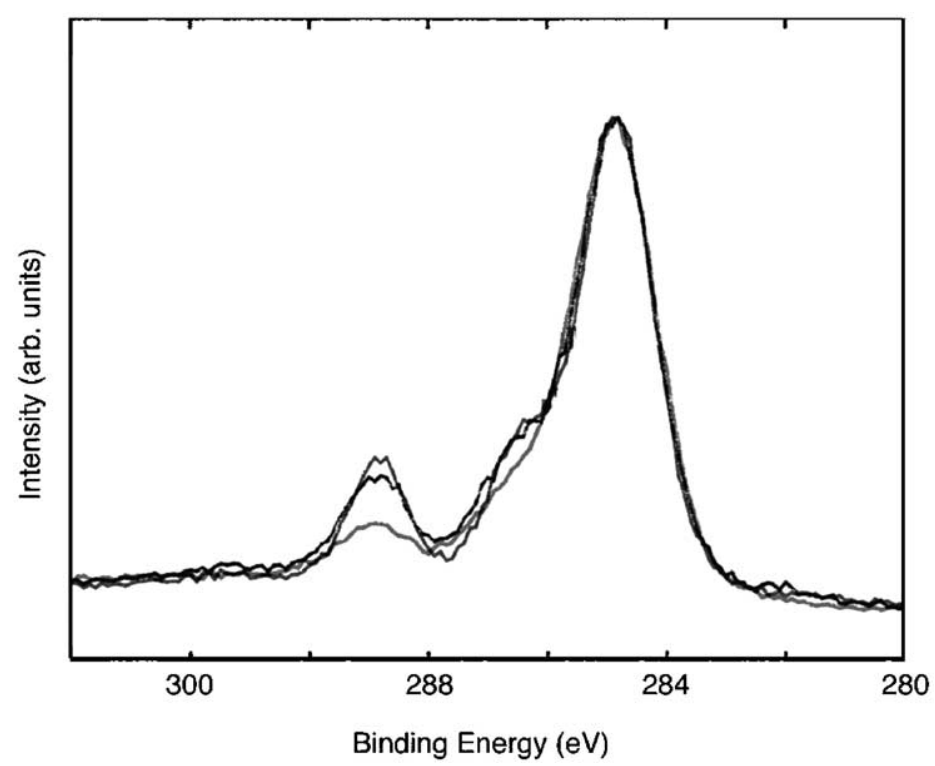

Fig. 1. Comparison of the $\mathrm{C} 1 \mathrm{~s}$ region of untreated PET film (upper curve at $288.5 \mathrm{eV}$ ) to $248 \mathrm{~nm}$ irradiated (middle) and $193 \mathrm{~nm}$ irradiated (lowest).

force microscopy (AFM) using a digital instruments "NanoScope ${ }^{\circledR}$ IV" scanning probe microscope in intermittent contact ("tapping") mode. The scan rate was set at $0.5 \mathrm{~Hz}$ to scan over multiple $2 \mu \mathrm{m} \times 2 \mu \mathrm{m}$ sampling areas. Second-order flattening was applied to the data before surface roughness analysis.

\section{Results and discussion}

\subsection{XPS}

The interpretation of PET core level spectral lines is well established $[8,9]$. The average intensity ratio of $\mathrm{C}$

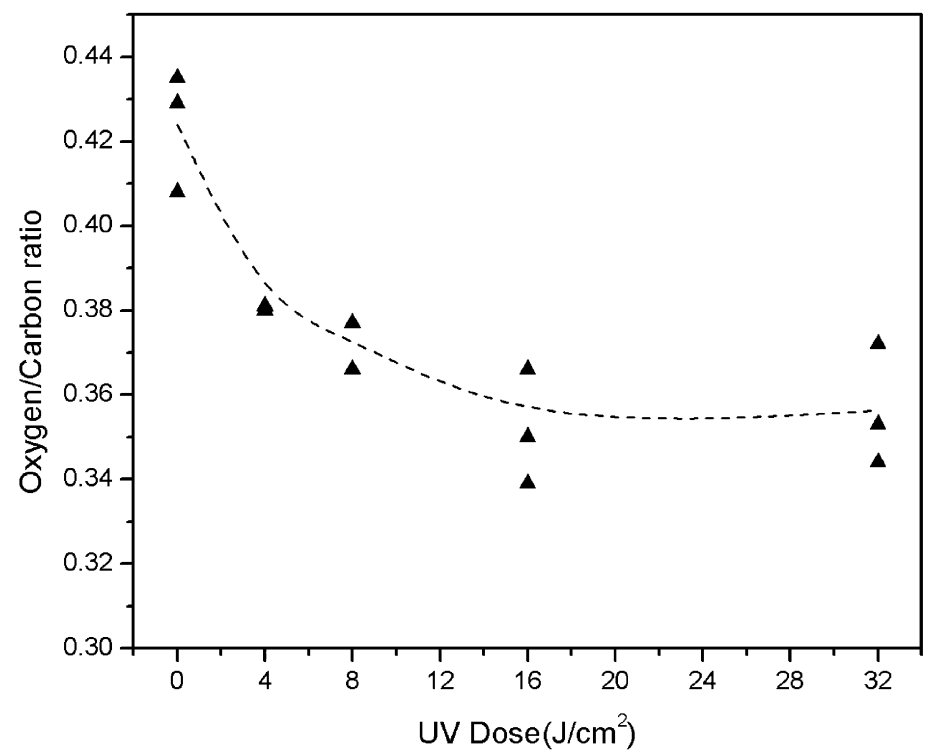

Fig. 2. Effect of $172 \mathrm{~nm}$ UV on surface oxygen content as determined by XPS. The dashed line is only a guide for the eye. 


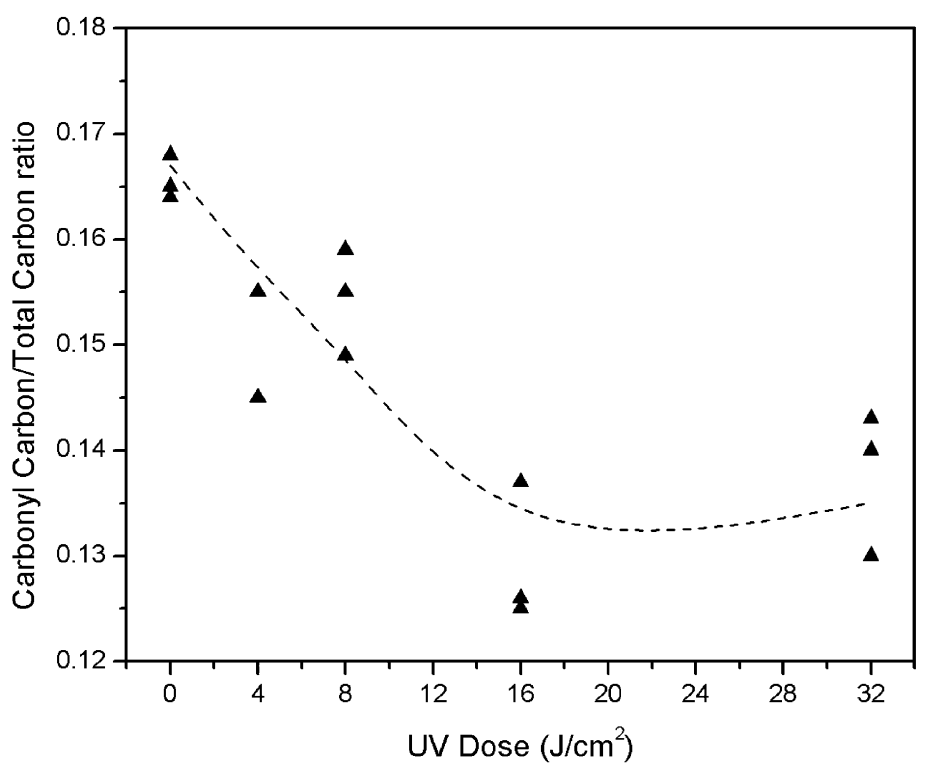

Fig. 3. Effect of $172 \mathrm{~nm} \mathrm{UV}$ on relative $\mathrm{C}=\mathrm{O}$ content of surface carbon as determined by XPS. The dashed line is only a guide for the eye.

$1 \mathrm{~s}$ and $\mathrm{O} 1 \mathrm{~s}$ peaks from three untreated PET samples is $10.00 / 4.24$, which is close to the nominal value $10 / 4$. Fig. 1 shows data from the $\mathrm{C} 1 \mathrm{~s}$ region of the untreated and two laser-treated materials. All spectra were shifted so that the aliphatic carbon peaks appears at $284.6 \mathrm{eV}$ and normalized so that peak has the same height over background. They were not smoothed. The difference between the untreated material and that irradiated at $248 \mathrm{~nm}$ is small indeed, less than the noise in the previously reported [1] spectra. Further, that material received only $12 \mathrm{~mJ} / \mathrm{cm}^{2}$ of $248 \mathrm{~nm}$ light, versus $17 \mathrm{~mJ} / \mathrm{cm}^{2}$ here. In contrast, it is evident $12 \mathrm{~mJ} /$

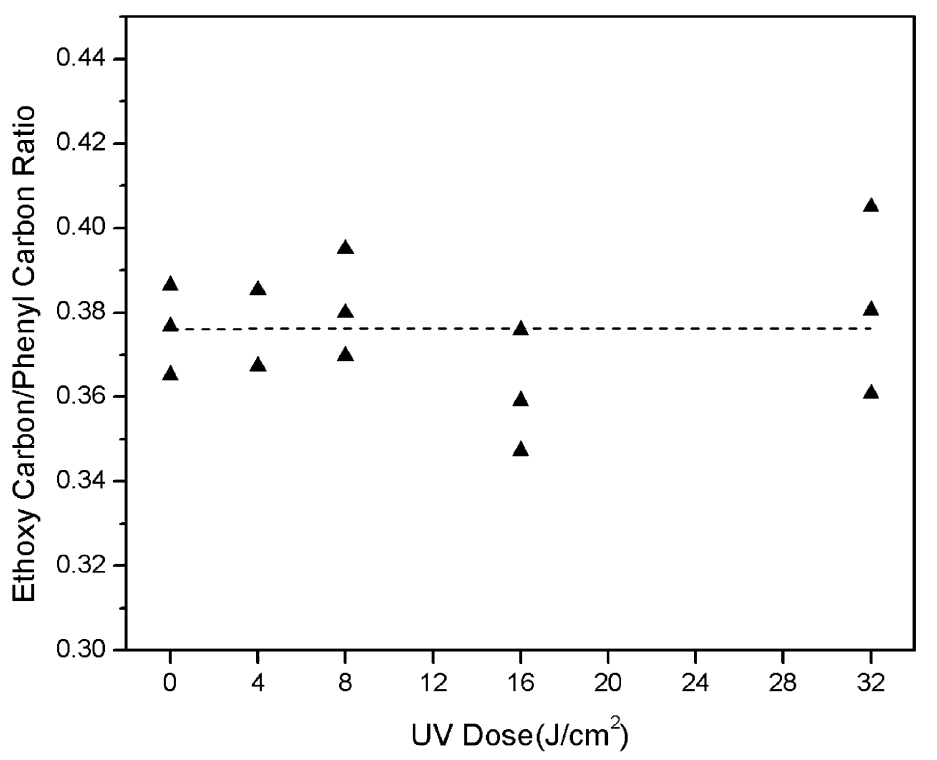

Fig. 4. Effect of $172 \mathrm{~nm}$ UV on $I_{\mathrm{C}-\mathrm{O}} / I_{\mathrm{C} \text { aromatic }}$ as determined by XPS. The dashed line is only a guide for the eye. 


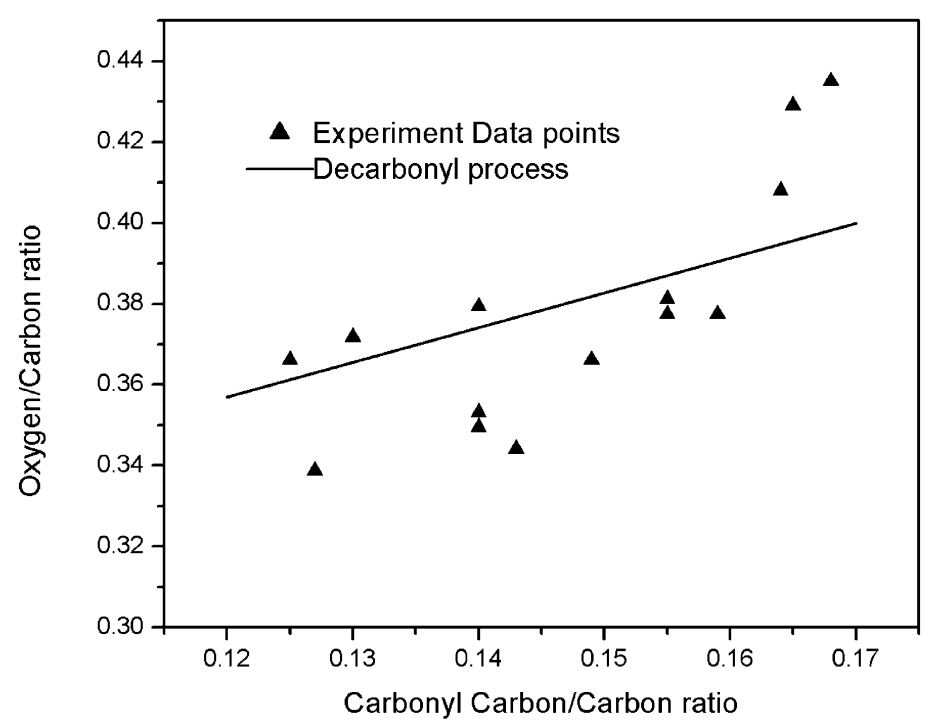

Fig. 5. Relationship between relative surface oxygen content and relative carbonyl content. The solid line is a model calculation assuming that oxygen content changes only via carbonyl content change.

$\mathrm{cm}^{2}$ at $193 \mathrm{~nm}$ leads to significant loss of both oxygenrelated carbon species.

Fig. 2 presents the effect of $172 \mathrm{~nm}$ UV irradiation on the surface oxygen to total carbon ratio for three equivalent samples. The ratio decreases with increasing UV dose upto about $16 \mathrm{~J} / \mathrm{cm}^{2}$, and then levels-off at about one-sixth less than its original value. For films receiving $32 \mathrm{~J} / \mathrm{cm}^{2}$, the decrease of $\mathrm{O} / \mathrm{C}$ ratio relative to that of untreated material was $8-10 \%$ greater for films analyzed as-treated, compared to films rinsed before analysis. The unwashed film was also somewhat tacky to touch.

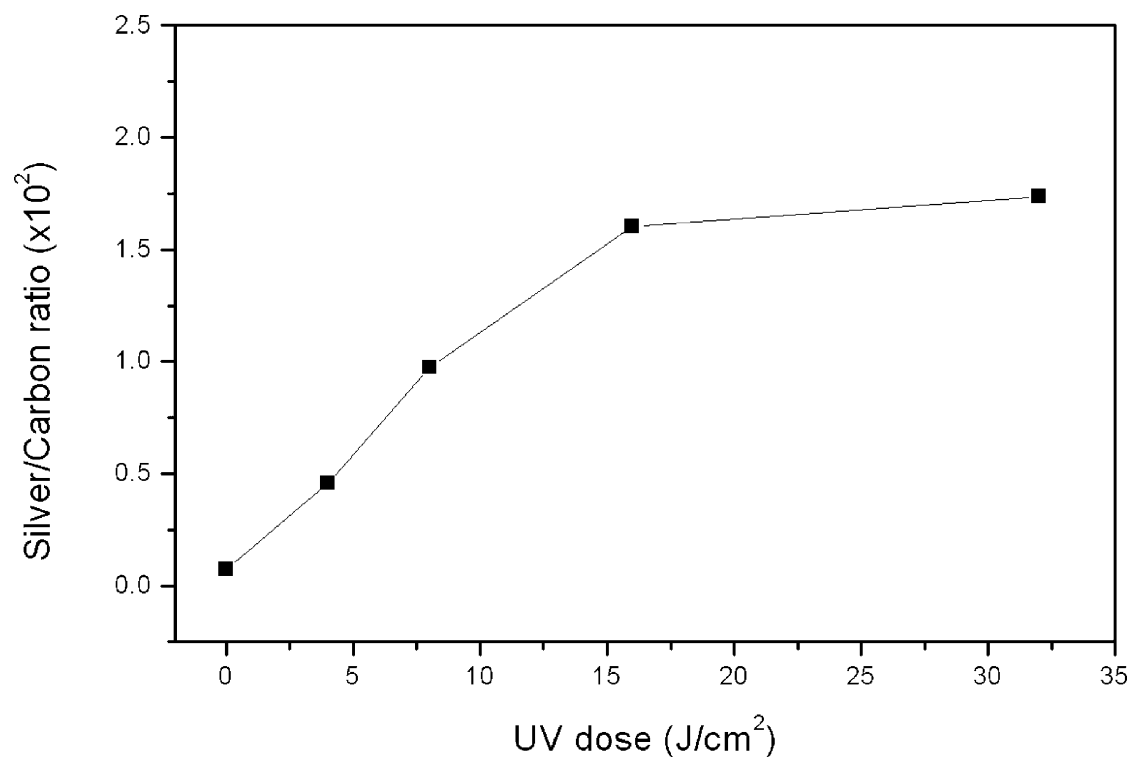

Fig. 6. Relative surface silver content as a function of UV dose. 

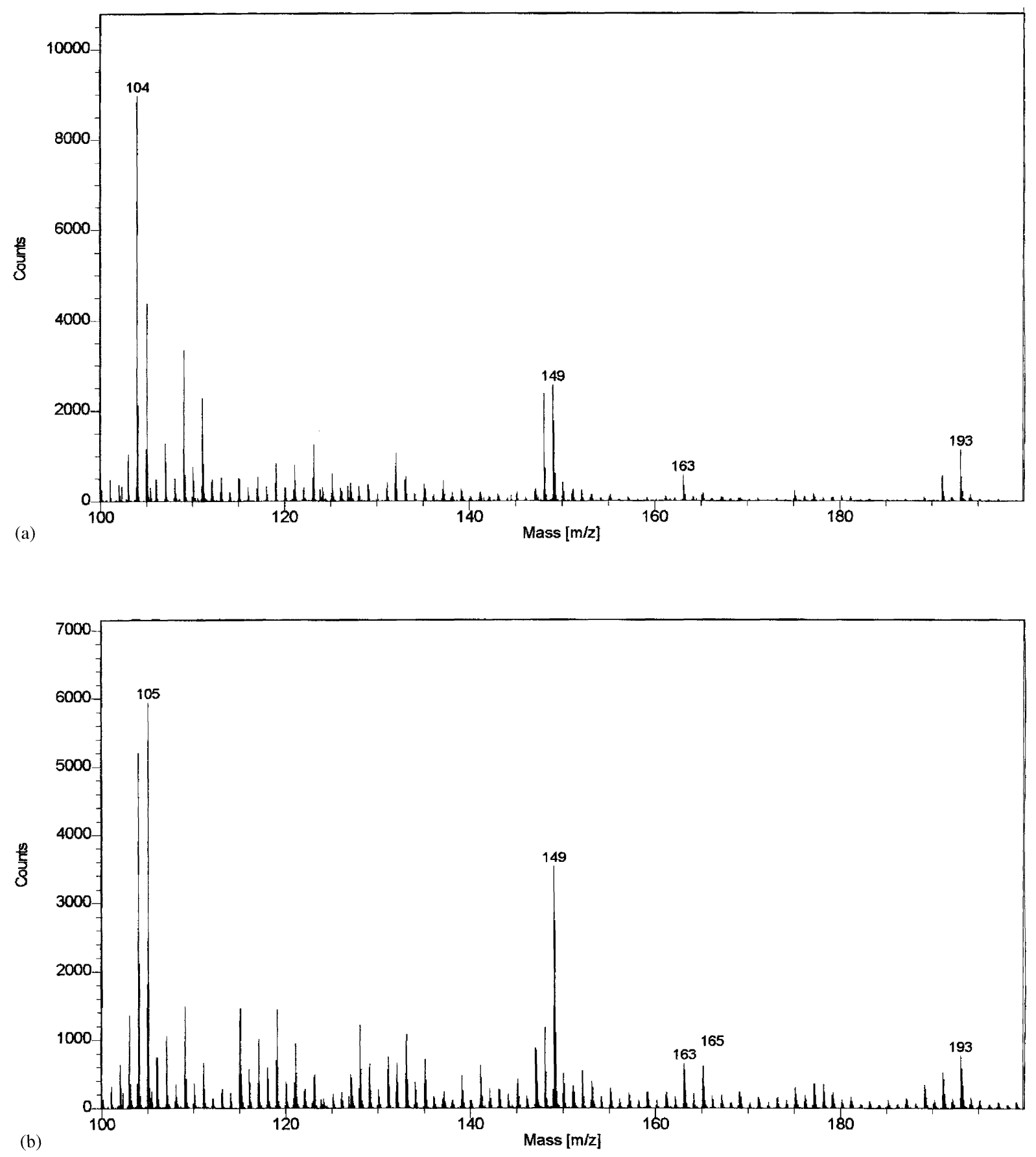

Fig. 7. ToF/SIMS positive ion spectra of: (a) untreated PET; (b) PET subject to $16 \mathrm{~J} / \mathrm{cm}^{2}$ of $172 \mathrm{~nm}$ UV. 
Fitting the individual carbon peak componentscarbonyl, ethoxy, and aliphatic-gives further insight. In untreated material, the measured average intensity ratio was $0.82 / 1.13 / 3.00$, in reasonable agreement with the nominal value $1 / 1 / 3$ and with previous studies of high purity PET $(0.96 / 1.12 / 3.00)$ [10]. Fig. 3 shows that the loss of carbonyl carbon is similar to the decrease of total oxygen/carbon ratio, in contrast with the constancy of ethoxy carbon (Fig. 4). In fact oxygen loss closely tracks carbonyl carbon loss (Fig. 5).

The silver trifluoroacetate derivatization provides yet another view [3]. Silver trifluoroacetate reacts with PET surface carboxylic acid groups to<smiles>CCCOC(=O)c1ccc(C(=O)OCCC)cc1</smiles>

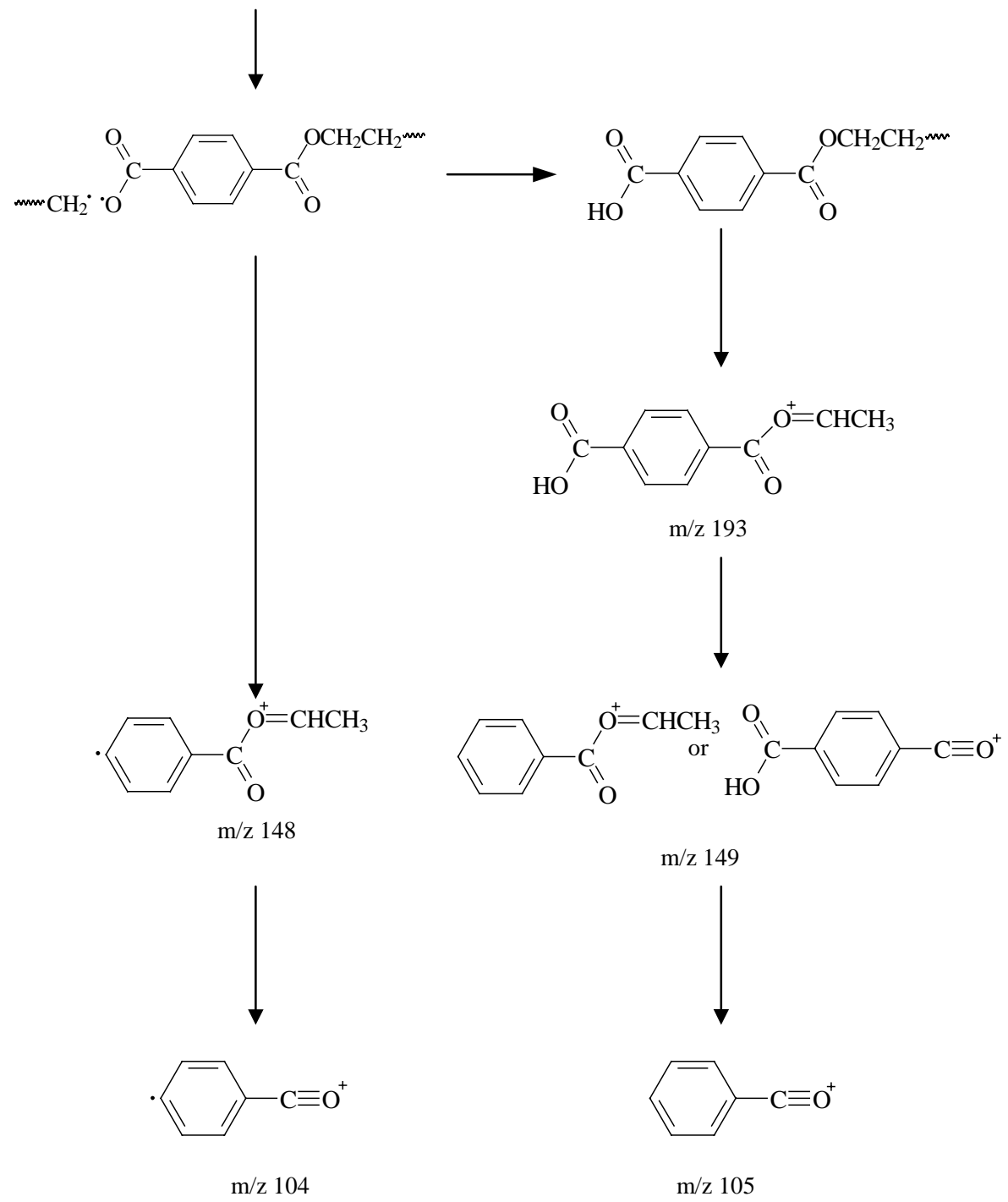

Scheme 1. Generation of characteristic mass fragments of PET. 

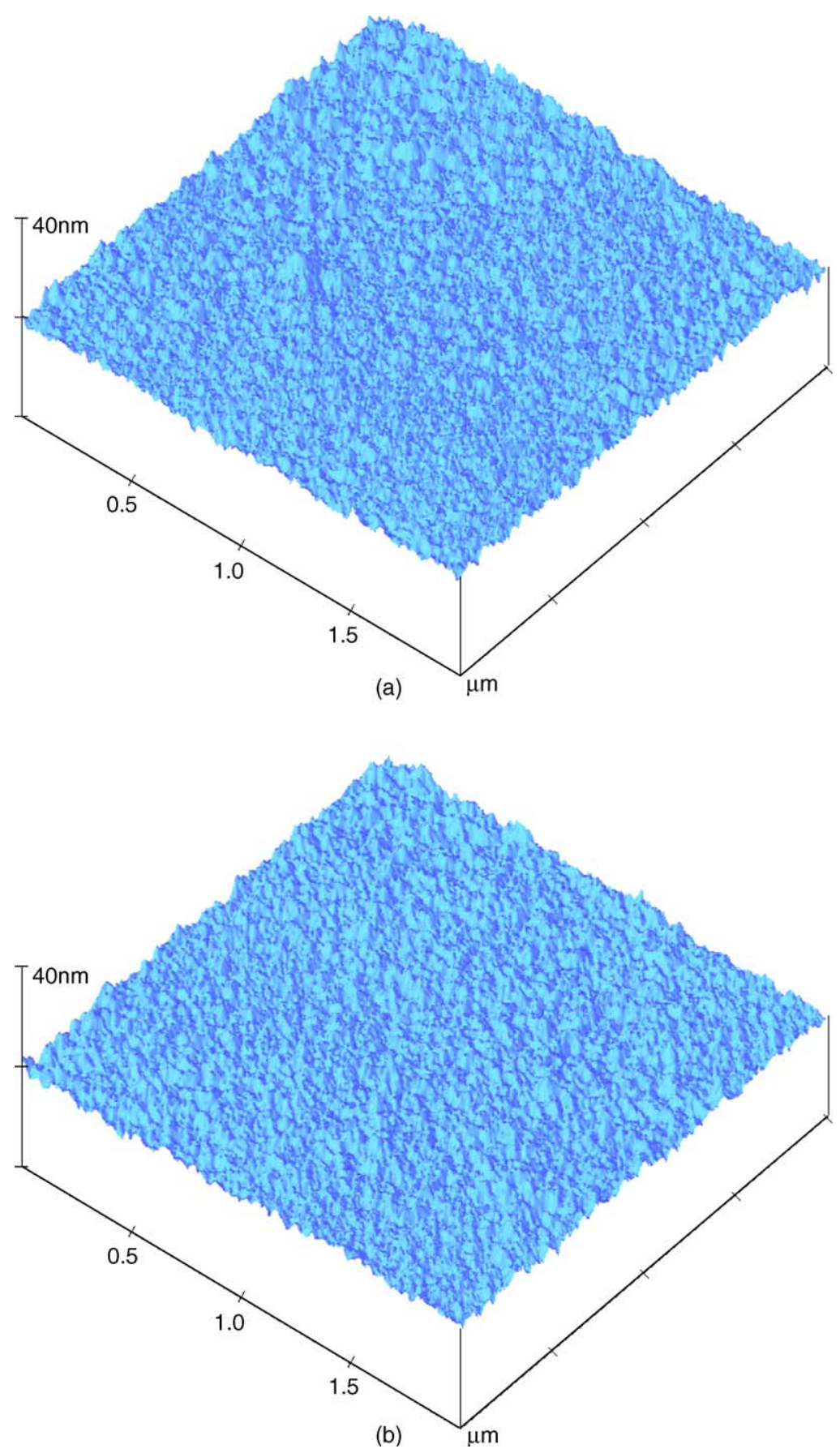

Fig. 8. Topographic images of: (a) untreated; (b) $16 \mathrm{~J} / \mathrm{cm}^{2}$ irradiated; (c) $32 \mathrm{~J} / \mathrm{cm}^{2}$ irradiated PET films. 


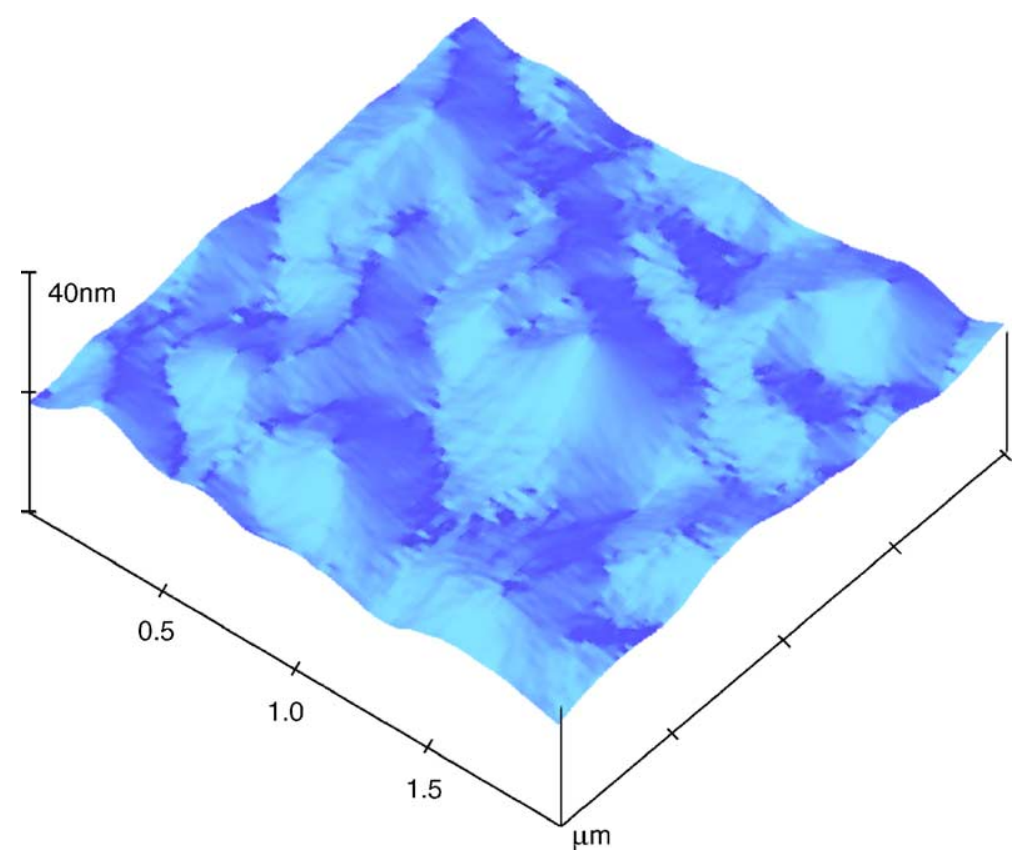

Fig. 8. (Continued).

yield surface bound silver carboxylate salts according to:

$$
-\mathrm{COOH}+\mathrm{CF}_{3} \mathrm{COOAg} \rightarrow-\mathrm{COOAg}+\mathrm{CF}_{3} \mathrm{COOH}
$$

Fig. 6 shows that $\mathrm{Ag} / \mathrm{C}$ ratio increases with $\mathrm{UV}$ dose upto about $16 \mathrm{~J} / \mathrm{cm}^{2}$, suggesting that formation of carboxylic acid end groups accompanies the other changes. Since, the derivatization reaction proceeds only for surface-exposed acid groups, while the XPS signal originates from at least the top few nanometers, the $\mathrm{Ag} / \mathrm{C}$ ratio likely understates the surface acid group concentration.

\subsection{ToF/SIMS}

ToF/SIMS provides the most sensitive currently available view of polymer surface chemistry [6,7]; PET has been extensively investigated [11]. As shown in Fig. $7 \mathrm{a}, m / z=104,105,148,149,193$ are characteristic peaks of PET. Their formation can be summarized in Scheme 1 [11]. Upon ion bombardment, the weakest bond disassociates and may form a carboxy and alkyl radical pair. The active carboxy radical can extract hydrogen from neighboring molecules to form end carboxylic group. Further ion bombardment may cleave another weak $\mathrm{C}-\mathrm{O}$ bond and form the characteristic 193 mass peak. Subsequent fragmentation leads to 149 and 105 mass peaks. Alternatively, the carboxy radical may not have time to extract hydrogen before being lift off surface so that 148 and 104 mass peaks form with one proton short. The mass peaks that appear in the UV-modified PET sample are similar to the original PET sample except for the difference in the relative intensity (Fig. 7b). In the UV-modified PET sample, the intensity ratios of high mass fragment $\mathrm{m} / \mathrm{z} 149$ (or $m / z=105$ ) to low mass fragment $\mathrm{m} / z 148$ (or $m / z=104$ ) are much higher (two to three-fold) than the original PET. It may be attributed to pre-existing polymer end groups in favor of producing $149 \mathrm{~m} / \mathrm{z}$ and $105 \mathrm{~m} / \mathrm{z}$ peaks instead of their radical counterparts. In addition, peak intensity at $m / z=165$ also increases dramatically for the UV-treated material, perhaps originating from decarbonylation products.

\section{3. $A F M$}

Topographical analysis was carried out with AFM comparing UV-treated and untreated PET samples. Fig. 8 shows topographic images of untreated, $16 \mathrm{~J} /$ 
$\mathrm{cm}^{2}$ irradiated and $32 \mathrm{~J} / \mathrm{cm}^{2}$ irradiated films. The rootmean-square (RMS) surface roughness for samples that received $16 \mathrm{~J} / \mathrm{cm}^{2}$ or less was between 1 and $2 \mathrm{~nm}$, but increased to above $4 \mathrm{~nm}$ for samples subjected to $32 \mathrm{~J} / \mathrm{cm}^{2}$. Together with the XPS data showing that $32 \mathrm{~J} / \mathrm{cm}^{2}$ dose samples have similar oxygen/carbon ratio, carbonyl/carbon ratio and $\mathrm{Ag} /$ carbon ratio to those of $16 \mathrm{~J} / \mathrm{cm}^{2}$ dose samples, it suggests that further irradiation beyond $16 \mathrm{~J} / \mathrm{cm}^{2}$ may lead to low molecular weight species that can be rinsed away with isopropanol. This is also consistent with the slightly lower oxygen/carbon ratio of $32 \mathrm{~J} / \mathrm{cm}^{2} \mathrm{UV}$-irradiated PET surface prior to isopropanol rinsing, which has an oxygen/carbon ratio of about $8 \%$ less than that of the isopropanol rinsed sample. The observed cone structures in UV-etched $32 \mathrm{~J} / \mathrm{cm}^{2}$ sample have diameter ranging from tens of nanometers to a few hundred nanometers, in good agreement with PET spherulites dimension $[12,13]$. This suggests that crystalline PET may be more resistant to degradation by deep UV light than amorphous material.

\section{Conclusion}

The effect of $172 \mathrm{~nm} \mathrm{Xe} \mathrm{excimer} \mathrm{lamp} \mathrm{irradiation}$ on PET in the absence of oxygen upto $16 \mathrm{~J} / \mathrm{cm}^{2}$ is dominated by carbonyl elimination and acid group formation, in contrast with the effect of irradiation at other deep UV wavelengths seen here and in previous studies. Further work is needed to definitively elucidate the relationship if any, carbonyl elimination and acid group formation. At UV dose levels higher than
$16 \mathrm{~J} / \mathrm{cm}^{2}$, differential etching roughens semi-crystalline PET surface.

\section{Acknowledgements}

We are grateful for helpful discussions with Dr. Michael W. Gurnick of DuPont Teijin Films and with Dr. Katherine M. Stika and Dr. Dennis J. Walls of DuPont. We also thank Amy Wilkerson for acquiring ToF/SIMS data.

\section{References}

[1] D.S. Dunn, A.J. Ouderkirk, Macromolecules 23 (1990) 770.

[2] M. Chtaib, E.M. Roberfroid, Y. Novis, J.J. Pireaux, R. Caudano, P. Lutgen, G. Feyder, J. Vac. Sci. Technol. A 7 (1989) 3233.

[3] S. Lazare, R. Srinivasan, J. Phys. Chem. 90 (1986) 2124.

[4] D. Praschak, T. Bahners, E. Schollmeyer, Appl. Phys. A 66 (1998) 69.

[5] U. Kogelschatz, H. Esrom, J.-Y. Zhang, I.W. Boyd, Appl. Surf. Sci. 168 (2000) 29.

[6] A. Benninghoven, Angew. Chem. Int. Ed. Engl. 33 (1994) 1023.

[7] K. Wien, Nucl. Inst. Meth. Phys. Res. B 131 (1997) 38.

[8] D. Clark, CRC Crit. Rev. Solid State Mater. Sci. 8 (1978) 1.

[9] D.W. Dwight, J.E. McGrath, J.P. Wightman, J. Polym. Sci., Appl. Polym. Symp. 34 (1978) 35.

[10] G. Beamson, D. Briggs, High resolution XPS of organic polymers, The Scienta ESCA300 Database, Wiley, England, 1992, p. 174.

[11] G.J. Leggett, J.C. Vickerman, D. Briggs, M.J. Hearn, J. Chem. Soc., Faraday Trans. 88 (1992) 297.

[12] G.E. Sweet, J.P. Bell, J. Polym. Sci., Phys. Ed. 16 (1978) 1935.

[13] M.W. Gurnick, DuPont Tejin Films, Private communication. 